\title{
A Cross Sectional Study on Knowledge, Beliefs and Psychosocial Predictors of Shisha Smoking among University Students in Sharjah, United Arab Emirates
}

\author{
Coumaravelou Saravanan ${ }^{1 *}$, Amita Attlee ${ }^{2}$, Nabil Sulaiman ${ }^{1}$
}

\begin{abstract}
Background: Smoking is now prohibited in all educational institutions and other public places in the United Arab Emirates (UAE), but shisha smoking is considered as one of the major problems among the students population. This study aimed to identify the (a) prevalence of ever shisha, current shisha and shisha dependency smokers among university students in the University of Sharjah (UOS), (b) knowledge and belief differences among ever shisha, current shisha as well as shisha dependency smoking students, (c) relationship between precipitating factors and shisha dependency and (d) precipitating factors (stimulation, handling, pleasure, tension reduction, addiction (dependency), automatism (habit) and social interaction, parents smoking behavior, knowledge and beliefs about smoking predict shisha dependency among students in UOS. Materials and Methods: In this cross sectional study, 633 students participated from UOS, UAE. Knowledge and Belief scale, Modified Reason for Smoking Scale and Fagerstrom Test for Nicotine Dependence (FTND) were used to measure knowledge, beliefs, shisha dependency and predictive factors of smoking behavior among undergraduate students in UOS. Results: Nearly103 (16.3\%) of students were addictive to shisha smoking based on FTND. Students had adequate knowledge that smoking led to cardiac problems; however, their knowledge about the other consequences of smoking was inadequate and believed that smoking was not harmful. There was a significant positive relationship between addiction, pleasure, social interaction, habit, parental smoking behavior and shisha dependency behavior among current shisha dependency students. Habit, addiction, pleasure, social interaction and parental smoking were the predictors of shisha smoking dependency among this population. Step wise multiple regressions showed that social interaction was the highest significant predictor for shisha dependency behavior. Conclusions: Hence, there is a need to enhance the knowledge and modify irrational beliefs about shisha smoking as these students possess inadequate knowledge about consequences of shisha smoking.
\end{abstract}

Keywords: Shisha smoking- precipitating factors- knowledge- beliefs

Asian Pac J Cancer Prev, 20 (3), 903-909

\section{Introduction}

Smoking in any form leads to major health hazards (National Center for Chronic Disease Prevention and Health Promotion, 2014). People use different methods of smoking such as cigarettes, shisha, electronic cigarettes etc (American Society of Clinical Oncology, 2018). In Middle East countries, smoking shisha is a popular method of tobacco use (Chattopadhyay, 2000). The practice of shisha smoking originated in the Eastern Mediterranean region and is gaining popularity in many western and Southeast Asian countries (Wong et al., 2016). Shisha is a water pipe made of clay, ornately carved metals or plastics, which enables smoking flavored tobacco as it is bubbled through water (Al-Kazwini et al., 2015). It is called 'nargile' in Turkey and Syria, or 'hookah' in India (Kader 2017). A shisha smoker inhales up to 200 times more smoke in a single session and is linked to higher rates of second hand smoking in contrast to a cigarette smoker (Aslam et al., 2014). Shisha smoking session lasts from about 45 to 60 minutes to several hours (St Helen et al., 2014), thereby increasing the associated health risks. For this reason American Society of Clinical Oncology (2018) warns people all over world not to smoke any forms as smoking affects the heath adversely.

In the United Arab Emirates (UAE), smoking shisha has also become a trendy pursuit among young people, available in different flavors and is a popular practice in family and other social gatherings (Al-Rawi et al., 2018; Moh'd Al-Mulla et al, 2008; Rizvi, 2016). Almost 15\% students at University of Sharjah in UAE were reported to smoke either cigarettes or shisha (Mandil et al, 2007). 
Further $18 \%$ university students smoked shisha in Dammam, Saudi Arabia (Taha et al., 2010). Certain misconceptions have been reported among people that nicotine content in shisha is lower than that in cigarettes, and water filters out all the toxic chemicals including tar, carbon monoxide and nicotine (Maziak et al., 2004; St Helen et al., 2014). Shisha smokers may not be aware that shisha smoke contains the same toxicants as cigarette smoke (American Society of Clinical Oncology, 2018; St Helen et al., 2014). Similarly, $70.3 \%$ of medical students reported that shisha is less addictive than cigarettes and they believed that there is no nicotine in shisha smoking (Al-Naggar and Bobryshev, 2012). Further shisha smokers may believe that smoking shisha relaxes their minds and enhances their pleasure. However, medical organizations such as American Society of Clinical Oncology (2018); World Health Organization (2018) warn youngsters not to smoke any type of substances as these are dangerous to them as well as for society. Therefore, identifying knowledge and beliefs related to shisha dependency would be useful for Sharjah student population as no studies have been conducted in this country.

Athamneh et al., (2015) cited in his article that shisha smoking is culturally accepted and its practice is less likely avoidable amongst most of the social gatherings in Arab countries (Kandela, 2000). Those parents who tend to smoke shisha at their homes, their children are also prone for smoking shisha at the younger age (Kader, 2017). Many shisha smokers think that shisha smoking gives pleasure, enhances intimacy in social gatherings, relaxes mood, smells sweet and helps deal with pressure, but they are not aware that smoking shisha is indirectly addictive physically and mentally, and leads to major heath hazardous (Bahelah et al., 2016; Mental Health Foundation, 2018; Omotehinwa et al, 2018). Despite the strong awareness by various government and private organizations that shisha can even be more dangerous than cigarettes, people still smoke shisha may be due to addiction and the belief of pleasure enhancement and reduction of tension (Al-Rawi et al., 2018; Amin et al., 2010; Ministry of Health and Prevention, 2018; Wan et al., 2016). Previous studies (Almutairi, 2016; Athamneh et al, 2015; Wong et al., 2015) identified major reasons and precipitating factors of smoking shisha such as peer pressure, pleasure, parental smoking behavior and tension reduction. However, these studies have been conducted in other countries but not in the UAE, and these previous studies did not identify other precipitating factors such as dependency, stimulation and habit etc. Therefore, there is a need to identify whether the major psychosocial precipitating factors contribute for shisha smoking or not among University of Sharjah students' perspectives. The result of this study would be useful for health authorities in the UAE and communities to target the precipitation factor in smoking cessation treatment.

Based on our knowledge, no study has been conducted in UAE to measure various knowledge, beliefs and psychosocial precipitating factors among university students' population in the UAE. The specific objectives of the current study were:

- To assess the prevalence of ever shisha, current shisha and shisha dependency smoking among University students in Sharjah

- To assess the knowledge and belief differences among ever shisha, current shisha and shisha with nicotine dependency smoking students.

- To find relationship between precipitating factors (stimulation, handling, pleasure, tension reduction, addiction (dependency), automatism (habit), social interaction, parents smoking behavior, knowledge and beliefs about smoking) and shisha dependency among students

- To estimate the extent to which precipitating factors (stimulation, handling, pleasure, tension reduction, addiction (dependency), automatism (habit) and social interaction, parents smoking behavior, knowledge and beliefs about smoking) predict shisha dependency behavior among students.

\section{Materials and Methods}

\section{Participants}

In this cross sectional study, convenient sampling method was used to approach all male and female students pursuing any undergraduate program in UOS during the academic year 2017-2018. An online survey was created and administered after posting announcements (using UOS emails, Black Board educational software and word of mouth) to attract the students. A total of 640 students participated; however, data of 633 students was analyzed due to the incomplete responses from the remaining 7 students. The mean age of these participants was 20.9 years.

\section{Materials}

Socio Demographic Information Sheet: It is prepared for this study purpose to collect data regarding student's age, undergraduate program registered and smoking status (ever and current shisha smoker).

\section{Shisha Smoking Status}

A shisha smoker was defined as one who had smoked tobacco using an oriental tobacco pipe with a long flexible tube to a container where the smoke is cooled by passing through water. A shisha smoker is one who has smoked shisha in last 30 days prior to this survey was defined as "current shisha smokers". "Ever shisha smoker" is the one had not smoked shisha in last 30 days prior to survey but had tried in the past (even a puff). This criterion is based on the previous studies (Ghafouri et al, 2011; Habibullah, et al, 2011). The criteria of shisha smoking facilitate to distinguish between ever and current shisha smokers; however, no criteria is available to identify former shisha smokers.

\section{Fagerstrom Test for Nicotine Dependence (FTND; Fagerstrom and Furberg, 2008)}

FTND has been used to measure the level of shisha dependence among current shisha smokers. FTND consists of 6 items and scoring for each item may differ from question to question. FTND score ranges from 1 to 15 . Cut-off score for FTND scale would be low 
dependence (1-2), low to moderate dependence (3-4), and high dependence ( 5 and above). Smokers who score 3 to 4 considered as low to moderates nicotine dependency have to consider quitting smoking as they are vulnerable for high nicotine dependency. Smokers who score 5 and above considered highly dependent on nicotine dependency need treatment immediately (Fagerstrom and Furberg 2008). Shisha dependency in participants in the present study was considered in those who scored 5 and above in FTND. Based on previous study suggestion we replaced cigarette' with 'shisha' in the questionnaire (Maziaka, Warda, Soweidc, and Eissenberg, 2005). The test-retest reliability of FTND is 0.67 and has been used in many researches (Auf et al., 2012; Pineiro et al., 2013).

\section{Modified Reason for Smoking Scale (MRSS; Berlin et al., 2003)}

MRSS has been used in this research to find the precipitating factors and predictors of shisha smoking behavior. The original MRSS consisted of 21 items and scored in five likert scale format: never (1), rarely (2), once in a while (3), most of the time (4), and always (5). However, the latest version consists of 19 instead of 21 items. The present study used 19 items. The test consists of 7 categories which are stimulation, handling, pleasure, tension reduction, addiction (dependency), automatism (habit) and social interaction. The score for each category ranges from 3 to 15 . The test-retest reliability for the MRSS is 0.83 (Berlin et al., 2003).

\section{Knowledge and Beliefs Scale}

This scale was developed based on the Global Adult Tobacco Survey (GATS), 2008. All these scales are measured in three point likert scale (yes/no/don't know). The responses of "no" and "don't know" indicate the lack of knowledge and beliefs about smoking. This scale had been widely used by various researchers (Ali, et al., 2010; Nicholson, 2015) to measure the knowledge and beliefs about smoking. Obaid et al., (2014) identified the Cronbach alpha value of 0.85 .

\section{Procedure}

After obtaining the ethical and research approval from UOS, the researchers sent an online invitation to all undergraduate students through official UOS email IDs to participate in this study. The invitation letter included the brief description, aim and importance of this study and participation eligibility. Nonsmokers were also invited to participate in order to identify their knowledge and beliefs about smoking. Online survey was posted that included the consent form, study information sheet and questionnaire. Participants were instructed to clarify their doubts through the email address of the authors stated in the information sheet.

\section{Statistical analysis}

Descriptive statistics was used to measure the prevalence of shisha smoking based on shisha practice among the students. Cross tabulation was used to identify knowledge differences among ever, current and current shish nicotine dependency students. Correlation was
Shisha Smoking, Precipitating Factors, University Students

used to measure the relationship between precipitation factors (stimulation, handling, pleasure, tension reduction, addiction, automatism, social interaction, parents smoking behavior, knowledge and beliefs) and shisha smoking dependency among students. In addition, stepwise multiple regression analysis was used to identify which precipitation factors predict the smoking behavior. The data was tested for significance of difference at $p<0.05$.

\section{Results}

\section{Prevalence of shisha smokers}

Table 1 shows that out of 633 students who participated in the on-line survey, $246(38.9 \%)$ were current shisha smokers and the rest 284 (44.9\%) reported ever smoking shisha. Based on FTND test score, 103 (16.3\%) students were addicted and dependent on shisha smoking. The results have been analyzed and interpreted for only the current shisha dependency students as they are vulnerable for consequences.

\section{Differences in knowledge and beliefs among ever, current and current shisha dependent smokers}

Table 2 shows the level of knowledge regarding shisha smoking among $(\mathrm{n}=633)$ students. Based on the 9-item questionnaire, it was evident that the students had inadequate knowledge regarding the adverse health effects of shisha smoking. Except their relatively higher awareness about its consequences on heart diseases (69.9\% responded "yes"), the awareness levels for other diseases ranged between 3.6\% (is shisha smoking is more addictive than cigarettes) to $42.3 \%$ (does smoking cause lung cancer). More startling was the fact that the students had wrong conceptions as indicated by their high percentages who responded as "No" to the questions. Further, some of the students had no knowledge about the health consequences of shisha smoking as they reported "don't know".

\section{Correlation between shisha smoking dependency behavior and other precipitating factors}

Table 3 shows a significant positive relationship between addiction, pleasure, social interaction, habit, parental smoking behavior and shisha dependency behavior among current shisha dependency students. However, this study could not find significant correlation between tension reduction, stimulation, handling, general knowledge and beliefs about shisha and shisha dependency behavior.

\section{Predictors of shisha dependency behavior}

A stepwise multiple regression models was run with those independent (predictor) variables including

Table 1. Prevalence of Smoking Behavior $(n=633)$

\begin{tabular}{lc}
\hline Shisha levels & No (\%) \\
\hline Ever smoked shisha & $284(44.9)$ \\
Current shisha smokers & $246(38.9)$ \\
Current shisha smokers with dependency on & $103(16.3)$ \\
shisha smoking & \\
\hline
\end{tabular}

Asian Pacific Journal of Cancer Prevention, Vol $20 \quad \mathbf{9 0 5}$ 
Table 2. Differences in Knowledge and Beliefs among Ever, Current and Current Shisha Dependent Smokers

\begin{tabular}{|c|c|c|c|c|}
\hline Knowledge and beliefs/ levels & $\begin{array}{c}\text { Ever shisha }(\mathrm{N}=284) \\
\text { No }(\%)\end{array}$ & $\begin{array}{c}\text { Current shisha }(\mathrm{n}=246) \\
\text { No }(\%)\end{array}$ & $\begin{array}{l}\text { Current shisha nicotine }(\mathrm{n}=103) \\
\text { No }(\%)\end{array}$ & $\begin{array}{l}\text { Over all } \\
\text { No }(\%)\end{array}$ \\
\hline \multicolumn{5}{|l|}{ Does smoking cause lung cancer? } \\
\hline Yes & $198(55.6)$ & $55(31.6)$ & $15(14.6)$ & $268(42.3)$ \\
\hline No & $118(33.1)$ & $119(68.4)$ & $88(85.4)$ & $325(51.3)$ \\
\hline Don't know & $40(11.2)$ & $0(0.0)$ & $0(0)$ & $40(6.3)$ \\
\hline \multicolumn{5}{|l|}{ Does smoking cause stroke? } \\
\hline Yes & $11(3.1)$ & $6(3.4)$ & $11(10.7)$ & $28(4.4)$ \\
\hline No & $308(86.5)$ & $132(75.9)$ & $82(79.6)$ & $522(82.5)$ \\
\hline Don't know & $37(10.4)$ & $36(20.7)$ & $10(9.7)$ & $82(13.1)$ \\
\hline \multicolumn{5}{|c|}{ Does smoking cause heart disease? } \\
\hline Yes & $288(80.9)$ & $82(47.1)$ & $72(69.9)$ & $442(69.9)$ \\
\hline No & $41(11.5)$ & $75(43.1)$ & $23(22.3)$ & $139(22.0)$ \\
\hline Don't know & $27(7.6)$ & $17(9.8)$ & $8(7.8)$ & $52(8.2)$ \\
\hline \multicolumn{5}{|c|}{ Does smoking cause gum infection? } \\
\hline Yes & $16(4.5)$ & $12(6.9)$ & $9(8.7)$ & $37(5.8)$ \\
\hline No & $338(94.9)$ & $161(92.5)$ & $91(88.3)$ & $590(93.2)$ \\
\hline Don't know & $2(0.6)$ & $1(0.6)$ & $3(2.9)$ & $6(0.9)$ \\
\hline \multicolumn{5}{|c|}{ Does smoking cause hypertension? } \\
\hline Yes & $31(8.7)$ & $6(3.4)$ & $10(9.7)$ & $47(7.4)$ \\
\hline No & $320(89.9)$ & $162(93.1)$ & $92(89.3)$ & $574(90.7)$ \\
\hline Don't know & $5(1.4)$ & $6(3.4)$ & $1(1.0)$ & $12(1.9)$ \\
\hline \multicolumn{5}{|c|}{ Does smoking cause sexual dysfunction? } \\
\hline Yes & $20(5.6)$ & $5(2.9)$ & $6(5.8)$ & $31(4.9)$ \\
\hline No & $334(93.8)$ & $152(87.4)$ & $92(89.3)$ & $578(91.3)$ \\
\hline Don’t know & $2(0.6)$ & $17(9.8)$ & $5(4.9)$ & $24(3.8)$ \\
\hline \multicolumn{5}{|c|}{ Is shisha more addictive than cigarettes? } \\
\hline Yes & $8(2.3)$ & $11(6.3)$ & $4(3.9)$ & $23(3.6)$ \\
\hline No & $264(74.4)$ & $147(84.5)$ & $54(52.4)$ & $465(73.6)$ \\
\hline Don’t know & $83(23.4)$ & $16(9.2)$ & $45(43.7)$ & $144(22.8)$ \\
\hline \multicolumn{5}{|c|}{ Does the water in shisha filters not the toxins? } \\
\hline Yes & $35(9.8)$ & $36(20.7)$ & $10(9.7)$ & $81(12.8)$ \\
\hline No & $313(87.9)$ & $105(60.3)$ & $81(78.6)$ & $499(78.8)$ \\
\hline Don’t know & $8(2.2)$ & $33(19)$ & $12(11.7)$ & $53(8.4)$ \\
\hline \multicolumn{5}{|c|}{ Is lot of nicotine in shisha tobacco smoking? } \\
\hline Yes & $27(7.6)$ & $53(30.5)$ & $24(23.4)$ & $104(16.5)$ \\
\hline No & $245(69.0)$ & $82(47.1)$ & $26(25.2)$ & $353(55.9)$ \\
\hline Don’t know & $83(23.4)$ & $39(22.4)$ & $53(51.5)$ & $175(27.7)$ \\
\hline
\end{tabular}

addiction, pleasure, social interaction, habit and parental smoking behavior significantly correlated with shisha smoking dependency student as the dependent (criterion) variable. Table 4 shows that $09 \%\left(\mathrm{R}^{2}=.092\right.$, $\mathrm{F}(1,101)=10.269 ; \mathrm{p}=.002)$ of parental smoking behavior; $15 \%\left(\mathrm{R}^{2}=.152, \mathrm{~F}(2,100)=8.979 ; \mathrm{p}=.000\right.$ of addiction;
$20 \%\left(\mathrm{R}^{2}=.208, \mathrm{~F}(3,99)=8.64 ; \mathrm{p}=.000\right)$ of habit and $25 \%\left(\mathrm{R}^{2}=.254, \mathrm{~F}(4,98)=8.35 ; \mathrm{p}=.000\right)$ social interaction significantly predicted shisha dependency smoking behavior. Pleasure was automatically excluded from the model.

Table 3. Correlation between Shisha Smoking Dependency Behavior and Other Precipitating Factors

\begin{tabular}{|c|c|c|c|c|c|c|c|c|c|c|}
\hline & & Addiction & Pleasure & $\begin{array}{l}\text { Tension } \\
\text { reduction }\end{array}$ & $\begin{array}{c}\text { Social } \\
\text { interaction }\end{array}$ & Stimulation & Habit & Handling & $\begin{array}{c}\text { Parental } \\
\text { smoking behavior }\end{array}$ & Knowledge \\
\hline \multirow{2}{*}{$\begin{array}{l}\text { Shisha } \\
\text { dependency } \\
\text { behavior }\end{array}$} & $\mathrm{R}$ & 0.207 & 0.198 & -0.098 & 0.203 & 0.1 & 0.258 & 0.156 & 0.304 & -0.73 \\
\hline & $\mathrm{p}$ & $0.36^{*}$ & $0.45^{*}$ & 0.325 & $0.040^{*}$ & 0.316 & $0.009 * *$ & 0.115 & $0.002 * *$ & 0.463 \\
\hline
\end{tabular}

$\mathrm{R}$ indicates correlation coefficient; ${ }^{*} \mathrm{P}<0.05$ level; $* * \mathrm{P}<0.01$ level 
Table 4. Predictors of Shisha Dependency Behavior

\begin{tabular}{lccc}
\hline Variable & $\mathrm{B}$ & $\mathrm{SE}$ & $\beta$ \\
\hline Parental smoking behavior & 0.345 & 0.108 & $0.304^{*}$ \\
$\begin{array}{l}\text { Parental smoking behaviour and } \\
\text { addiction }\end{array}$ & 0.116 & 0.043 & $0.247^{*}$ \\
$\begin{array}{l}\text { Parental smoking behaviour, } \\
\text { addiction and habit }\end{array}$ & 0.0 .97 & 0.037 & $0.236^{*}$ \\
$\begin{array}{l}\text { Parental smoking behaviour, } \\
\text { addiction, habit and social }\end{array}$ & 0.119 & 0.048 & $0.218^{*}$ \\
$\begin{array}{l}\text { interaction } \\
\text { *, indicate } \mathrm{P}<0.01 ; \text { SE, standard error }\end{array}$ & & & \\
\hline
\end{tabular}

\section{Discussion}

This study was conducted to identify the prevalence of shisha smoking, differences in knowledge and beliefs among ever, current and shisha dependency, and also at what extent precipitating factors such as stimulation, handling, pleasure, tension reduction, addiction, habit, social interaction, parents smoking behavior and knowledge about smoking predict shisha smoking dependency behavior among students from one of the leading universities in the UAE. In this present study the prevalence of shisha smoking among the UOS students was 277 (43.8\%). Similar to the current study, higher prevalence of shisha smoking was found among students studying in Kingdom of Saudi Arabia 44.1\% (Al-Turki, 2006), Iran 51\% (Ghafouri et al., 2011) and Pakistan 53.6 $\%$ (Jawaid et al., 2008). Comparatively, lower prevalence rates were reported among university students studying in South Africa 18.6\% (Senkubuge et al., 2012), United States of America 20\% (Eissenberg et al., 2008), Malaysia 30\% (Al-Naggar and Saghir, 2011) and Turkey 32.7\% (Poyrazoğlu et al., 2010). A higher prevalence reported in the present study may be attributed to the non-standardized criteria for shisha smokers (anyone who had smoked shisha in last 30 days is considered as a current shisha smoker) (Aryal and Bhatta, 2015; Habibullah et al., 2013), as well as to the cultural and social acceptance to shisha smoking in the UAE (Kader, 2010; Athamneh et al., 2015). For this reason, the results of this study categorized shisha dependency students from current shisha smokers as shisha dependency students are vulnerable for various physical and mental health problems.

This study showed inadequate levels of knowledge regarding the health consequences of shisha smoking among the university students. Relatively, higher proportion of students (69.9\%) acknowledged that shisha smoking was associated with heart diseases, consistent with the findings of a previous study conducted in Malaysia (AL-Naggar and Saghir, 2011). Earlier studies conducted in Saudi Arabia (Amin et al., 2010), Malaysia (AL-Naggar and Saghir, 2011) and Qatar (Jaam et al., 2016) are in agreement to the findings of the current study that the participants did not have adequate knowledge about different health complications such as cancer, gum diseases, sexual problems, stroke etc. related to shisha smoking. However, Al-Rawi et al., (2018) in their study on dental students in Sharjah documented that the participants believed that shisha was associated with various health complications. Further, lesser proportion of the students $(3.6 \%)$ in the present study aware that shisha was more addictive than cigarettes, in contrast to the study conducted by al Rawi et al., (2018) showed that dental students in Sharjah had adequate knowledge that shisha was more addictive than cigarettes. Higher knowledge adequacy levels among the students in Al Rawi et al., (2018) study may be attributed to the fact that the requirements of dental curriculum encompass the consequences of shisha smoking. In contrast, participants from heath science and medical programs in Malaysia showed a lower level of awareness that shisha was less harmful than cigarettes for health (AL-Naggar and Saghir, 2011; Ghafouri et al., 2011). Similar findings were documented in the participants from Saudi Arabia and Pakistan who believed that shisha is less harmful than cigarette as the smoke is passed through filter (Amin et al., 2010; Habibullah et al., 2013).

The present study showed addiction, pleasure, habit, parental smoking and social interaction as the significant predictors of shisha smoking behavior among UOS students. These findings are consistent with other studies conducted in Egypt and Saudi Arabia (Auf et al., 2012; Mandil et al., 2010b). Our study highlighted social interaction as one of the major precipitating factors of shisha smoking in comparison to addiction, habit and parental smoking behavior. This finding may be attributed to the religious and legitimate restriction on other forms of substance abuse; thereby, the students tended to smoke shisha when they were involved in any social interactions in cafeterias and other places (Taha et al., 2010). The present findings also found that parental smoking predicted shisha behavior among the students. Parents who smoke shisha may directly or indirectly affect their children to start smoking behavior (Baheiraei et al., 2015). In most of the Arab countries, there is low stigma attached to shisha smoking (Kelishadi et al., 2007) and it is considered more acceptable than cigarette smoking. However, some parents restrict their children to smoke shisha as they are afraid that the children might end up indulging into other substances too (Baheiraei et al., 2015). Based on this study result, this study strongly recommends parents not to smoke shisha in front of their children as their smoking behavior may stimulate their smoking attitude.

While the present study could not find stimulation, knowledge, tension reduction and handling as predictors of shisha smoking behavior, however, another study had earlier documented that the students smoked shisha to relieve negative affect (tension reduction) and for stimulation (Auf et al, 2012). Peer pressure could be one of the factors for stimulation of smoking shisha among students population (Al-Rawi et al., 2018). Similar to this study, knowledge was not one of the factors to predict shisha behavior (Al-Naggar and Saghir, 2011). This fact emphasizes that the students may have knowledge about consequences of shisha smoking, but they may be reluctant to quit smoking due to social pressure, habit and/ or addiction. Therefore, provide more awareness about shisha related health complication and include substance abuse workshop in a curriculum would reduce the shisha 
and other substance abuse among students population.

A high prevalence of shisha smoking among the university students in Sharjah presses the need to address this issue on a national and regional health agenda. Moreover, in order to estimate the prevalence of shisha smokers, there is a need to develop distinct criteria for shisha smokers, particularly in the Middle Eastern region as shisha is widely prevalent, and is most likely accepted in this society. The modified version of FTND is beneficial to confirm the shisha dependency (Maziak et al., 2005). Ever smoke and currently smoking shisha both had insufficient knowledge about smoking shisha. The precipitating factors contributing to shisha smoking dependency highlighted in this study should be addressed in the intervention strategies on smoke cessation. Shisha dependent smokers are more likely dependent on other form of smoking. Therefore, the university and other educational institutions need to provide health awareness workshops and related supportive services for students who smoke and not smoke any substances. Further, Ministry of Health needs to take strong public health measures in order to educate the youth that smoking shisha, in particular, and other forms of smoking are addictive and harmful to health.

This study has few limitations. The results of the study are not generalizable to all the students in UAE as the data were collected from one university in UAE. In addition, the study used the convenience sampling method to collect data from the participants. However, the University of Sharjah is one of the largest higher educational institutions in the country and the sample may be considered representative of university students in the UAE. Further, this study focused on selected precipitating factors of shisha smoking while factors such as mental illness and other substance abuse, not included, may also predict the shisha smoking behavior.

The present study categorizations of smokers are based on previous studies, but this criterion is less likely sufficient to warrant the shisha dependency (Saravanan and Heidhy, 2014). So this study recommends to clinically interviewing the smokers to confirm their shisha dependency levels. Further, this study recommends focusing on other western and private universities in UAE as there may be differences in the prevalence and precipitating factors for smoking. Third, this study recommends screening other type of smoking behavior among students who are dependent on shisha.

Overall, there was a high prevalence of shisha smoking among university students. Students have inadequate knowledge about health consequences of shisha smoking. Social interaction followed by addiction, habit and parental smoking behavior were the most significant precipitating factors to shisha smoking. Students have inadequate knowledge about health consequences of shisha smoking. Providing more biopsychosocial awareness about smoking shisha will most likely reduce the usage of shisha among students and also in the social gatherings. Students counseling units should offer anti-smoking cessation campaign for students to enhance their awareness about shisha complications and also modify their irrational beliefs about smoking shisha.

\section{Acknowledgements}

This research was approved and funded by the University of Sharjah (Project No.: 1701090317-P). There is no conflict of interest among the authors to publish this research. I like to say thank you to Mr. Ishan Antony who is a second year medical student from the Royal College of Surgeons in Ireland, helped us to find past literatures related to introduction part of this research.

\section{References}

Al-Kazwini AT, Said AJ, Sdepanian S (2015). Compartmental analysis of metals in Waterpipe smoking technique. $B M C$ Public Health, 15, 153.

Al-Naggar AR, Bobryshev YV (2012). Shisha smoking and associated factors among medical students in Malaysia. Asian Pac J Cancer Prev, 13, 5627-32.

AL-Naggar RA, Saghir FSA (2011). Water pipe (Shisha) smoking and associated factors among Malaysian university students. Asian Pacific J Cancer Prev, 12, 3041-7.

Al-Rawi NH, Alnuaimi AS, Uthman AT (2018). Shisha smoking habit among dental school students in the United Arab Emirates: Enabling factors and barriers. Int J Dent, 11, https://doi.org/10.1155/2018/2805103.

Al-Turki YA (2006). Smoking habits among medical students in central Saudi Arabia. Saudi Med J, 27, 700-3.

Almutairi KM (2016). Predicting relationship of smoking behavior among male Saudi Arabian college students related to their religious practice. J Relig Health, 55, 469-9.

American Society of Clinical Oncology (2017). Health risks of e-cigarettes, smokeless tobacco, and water pipes. Available at https://www.cancer.net. Accessed August 26, 2017.

Amin TT, Amr M, Zaza, BO, Suleman W (2010). Harm perception, attitudes and predictors of waterpipe (shisha) smoking among secondary school adolescents in al-hassa, Saudi Arabia. Asian Pac J Cancer Prev, 11, 293-1.

Aryal UR, Bhatta DN (2015). Perceived benefits and health risks of cigarette smoking among young adults: insights from a cross-sectional study. Tob Induc Dis, 13, 22-9.

Aslam HM, SaleemS, GermanS, Qureshi WA (2014). Harmful effects of shisha: literature review. Int Arch Me, 7, 16.

Athamneh L, Sansgiry SS, Essien EJ, Abughosh S (2015). Predictors of intention to quit waterpipe smoking: A survey of Arab Americans in Houston, Texas. $J$ Addict, 3, 1-11.

Auf RA, Radwan GN, Loffredo CA, et al (2012). Assessment of tobacco dependence in waterpipe smokers in Egypt. Int $J$ Tuberc Lung Dis, 16, 132-7.

Baheiraei A, Sighaldeh SS, Ebadi A, Kelishadi R, Majdzadeh $\mathrm{R}$ (2015). The role of family on hookah smoking initiation in women: a qualitative study. Glob J Health Sci, 7, 1-10.

Bahelah R, DiFranza J R, Fouad FM, et al (2016). Early symptoms of nicotine dependence among adolescent waterpipe smokers. Tob Control, 25, 127-34.

Berlin I, Singleton EG, Pedarriosse AM, et al (2003). The modified reasons for smoking scale: factorial structure, gender effects and relationship with nicotine dependence and smoking cessation in French smokers. Addiction, 98, 1575-83.

Chattopadhyay A (2000). Emperor Akbar as a healer and his eminent physicians. Bull Indian Inst Hist Med, 30, 151-7.

Eissenberg T, Ward KD, Smith-Simone S, Maziak W (2007). Waterpipe tobacco smoking on a U.S. College campus: prevalence and correlates. J Adolesc Health, 42, 526-9.

Fagerstrom K, Furberg H (2008). A comparison of the fagerstrom test for nicotine dependence and smoking prevalence across 
countries. Addiction, 103, 841-45.

Ghafouri N, Hirsch JD, Heydari G, et al (2011). Waterpipe smoking among health sciences university students in Iran: perceptions, practices and patterns of use. BMC Res Notes, 4, 496.

Global Adult Tobacco Survey (GATS) (2010). Core questionnaire with optional questions, Version 2.0. Atlanta, GA: Centers for Disease Control and Prevention.

Habibullah S, Ashraf J, Taseer, IH, et al (2013). Prevalence of shisha smoking in college, university and madrasa Students Aged 20-25 Years in Pakistan. Pak J Med Res, 52, 3-7.

Jaam M, Al-Marridi W, Fares H, et al ( 2016). Perception and intentions to quit among waterpipe smokers in Qatar: a cross-sectional survey. Public Health Action, 6, 38-43

Jawaid A, Zafar AM, Rehman TU, et al (2008). Knowledge, attitudes and practice of university students regarding waterpipe smoking in Pakistan. Int J Tuberc Lung Dis, 12, 1077-84.

Kader BA (2017). Smoking was never part of Emirati culture and tradition, expert says. Available at https://gulfnews.com/. Accessed July 26, 2017.

Kandela P (2000). Nargile smoking keeps Arabs in Wonderland. Lancet (London, England), 356, 1175.

Kelishadi R, Mokhtari MR, Tavasoli AA, et al (2007). Determinants of tobacco use among youths in Isfahan, Iran. Int J Public Health, 52, 173-9.

Mandil A, Hussein A, Omer H, Turki G, Gaber I (2007). Characteristics and risk factors of tobacco consumption among University of Sharjah students. East Mediterr Health J, 13, 1449-58.

Mandil A, BinSaeed A, Ahmad S, et al ( 2010). Smoking among university students: A gender analysis. J Infect Public Health, 4, 179-87.

Maziaka WE, Warda KD, Soweidc RAF, Eissenberg T (2005). Standardizing questionnaire items for the assessment of waterpipe tobacco use in epidemiological studies. Public Health, 119, 400-4.

Mental Health Foundtaion (2017). Smoking and mental health. available at https://www.mentalhealth.org.uk/a-to-z/s/ smoking-and-mental-health. Accessed Jan 12, 2017.

Ministry of Health and Prevention. Smoking Cessation Clinics services (2017). Available at http://www.mohap.gov.ae/en/ services/Pages/458.aspx. Accessed Jan 12, 2017.

Moh'd Al-Mulla A, Abdou Helmy S, Al-Lawati J, et al (2008). Prevalence of tobacco use among students aged 13-15 years in Health Ministers' Council/Gulf Cooperation Council Member States, 2001-2004. J Sch Health, 78, 337-43.

National Center for Chronic Disease Prevention and Health Promotion (US) Office on Smoking and Health (2014). The health consequences of smoking- 50 years of progress: A Report of the Surgeon General. Atlanta (GA): Centers for Disease Control and Prevention (US). Available at https:// www.ncbi.nlm.nih.gov/books/NBK179276/. Accessed at November 10, 2017.

Rizvi A (2016). Shisha the biggest smoking threat to health, Abu Dhabi study shows . Available at www.thenational.ae. Accessed at November 10, 2017.

Omotehinwa OJ, Japheths O, Damascene JL, Habtu M (2018). Shisha use among students in a private university in Kigali city, Rwanda: prevalence and associated factors. BMC Pub Health, 18, 713.

Obaid HA, Hassan MA, Mahdy NH, et al (2014). Tobacco use and associated factors among school students in Dubai, 2010: intervention study. East Mediterr Health J, 20, 765-73.

Piñeiro B, López-Durán A, Fernández del Río E, et al (2013). Gender differences in personality patterns and smoking status after a smoking cessation treatment. BMC Pub Health,
Shisha Smoking, Precipitating Factors, University Students

13, 306 .

Poyrazoğlu S, Sarli S, Gencer Z, Günay O (2010). Waterpipe (narghile) smoking among medical and non-medical university students in Turkey. Ups J Med Sci, 115, 210-6.

Senkubuge F, Ayo-Yusuf OA, Louwagie GM, Okuyemi KS (2012). Water pipe and smokeless tobacco use among medical students in South Africa. Nicotine Tob Res, 14, 755-60.

Saravanan C, Heidhy I (2014). Psychological problems and psychosocial predictors of cigarette smoking behavior among undergraduate students in Malaysia. Asian Pac J Cancer Prev, 15, 7629-34.

St Helen G, Benowitz NL, Dains KM, et al (2014). Nicotine and carcinogen exposure after waterpipe smoking in hookah bars. Cancer Epidemiol Biomarkers Prev, 23, 1055-66.

Taha AA, Sabra AA, Al-Mustafa ZZ, et al (2010). Water pipe (shisha) smoking among male students of medical colleges in the eastern region of Saudi Arabia. Ann Saudi Med, 30, 222- 6.

Wong LP, Alias H, Aghamohammadi N, Aghazadeh S, Wai Hoe VC (2016). Shisha smoking practices, use reasons, attitudes, health effects and intentions to quit among shisha smokers in Malaysia. Int J Environ Res Public Health, 13, 726-32.

World Health Organization (2018). Tobacco. Available at http://www.who.int/news-room/fact-sheets/detail/tobacco. Accessed at March 9, 2018.

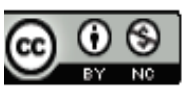

This work is licensed under a Creative Commons AttributionNon Commercial 4.0 International License. 